\title{
Os limites da percepção interna e a idolatria do autoconhecimento em Scheler
}

\author{
The limits of internal perception and the idolatry of \\ self-knowledge in Scheler
}

DANIEL RODRIGUES RAMOS ${ }^{a}$

\section{Resumo}

O artigo pretende discutir a possiblidade da percepção interna, delimitando-a do compreender da pessoa, que pode ser tanto compreensão do próximo como autocompreensão. Do mesmo modo, a percepção interna poder ser a percepção de si mesmo como percepção do outro. Parte-se, portanto, de uma indicação recorrente na fenomenologia de Scheler, de acordo com a qual a percepção interna não pode ser reduzida à autopercepção, entendida, sobretudo, no sentido de autoconsciência. Nesta direção, primeiramente, tenta-se uma definição fenomenológica do ato em questão, visando, sobretudo, libertá-lo das determinações idealistas enquanto autoconsciência e das compreensões subjetivistas, tais como a auto-observação e meio de autoconhecimento. Para tanto, demonstra-se que a percepção interna é uma direção de um único ato perceptivo e que o seu objeto não é uma forma lógica pura e vazia, mas sim a apreensão do eu material, concreto e singular. A intuição imediata e direta deste eu, então, aparecerá como a base sobre a qual se rompe com as duas interpretações supracitadas. Por fim, discute-se os elementos internos que contribuem para estes limites, em especial a fisiologia do sentido interno e os interesses do corpo-próprio (Leib), o que permite entender positivamente os limites e descrever os seus primeiros significados. A partir deste ganho fenomenológico, a investigação detém-se nos fatores externos, responsáveis por transformar a percepção interna em mero instrumento do autoconhecimento e por subjugá-la às metas e interpretações da cosmovisão natural, analisando brevemente as fontes da idolatria do autoconhecimento. Conclui-se que, na delimitação de sua possibilidade essencial, a desconsideração do papel psicofisiológico

\footnotetext{
a Universidade Federal do Recôncavo da Bahia (UFRB), Amargosa, BA, Brasil. Doutor em Filosofia, e-mail: dr.ramos@outlook.com.br
} 
do sentido interno, a transladação das leis e relações espaço-temporais próprias da esfera física para a psíquica e, consequentemente, a superposição da percepção externa sobre a interna em consonância com a interpretação sensualista da última são as principais fontes da ilusão denominada idolatria do autoconhecimento.

Palavras-chave: Fenomenologia da percepção. Sentido interno. Corporalidade. Autoconhecimento.

\section{Abstract}

The article intends to discuss the possibility of internal perception, delimiting it from the understanding of the person, which can be both the understanding of the neighbor and self-understanding. In the same way, the inner perception can be the perception of oneself as a perception of the other. It follows, therefore, from a recurrent indication in Scheler's phenomenology, according to which the internal perception cannot be reduced to selfperception, understood, above all, in the sense of self-consciousness. In this direction, a phenomenological definition of the act in question is first attempted, aiming, above all, to free it from idealistic determinations as self-consciousness and subjectivist understandings, such as self-observation and a means of self-knowledge. For this, it is demonstrated that the inner perception is a direction of a single perceptive act and that its object is not a pure and empty logical form, but the apprehension of the material, concrete and singular self. The immediate and direct intuition of this self, then, will appear as the basis on which it breaks with the two interpretations mentioned above. Finally, we discuss the internal elements that contribute to these limits, especially the physiology of the internal sense and the interests of the body-own (lived-body, Leib), which allows us to positively understand the limits and describe their first meanings. From this phenomenological gain, research focuses on external factors, responsible for transforming internal perception into a mere instrument of self-knowledge and subjugating it to the goals and interpretations of the natural worldview, briefly analyzing the sources of the idolatry of self-knowledge. It is concluded that, in the delimitation of its essential possibility, the disregard of the psychophysiological role of the inner sense, the translation of the laws and space-time relations proper of the physical sphere to the psychic and, consequently, the superposition of external perception consonance with the sensualist interpretation of the latter are the main sources of the illusion called idolatry of self-knowledge.

Keywords: Phenomenology of perception. Internal sense. Corporeality. Self-knowledge.

"Pois continuamos necessariamente estranhos a nós mesmos, [...] a nós se aplica para sempre a frase: "Cada qual é o mais distante de si mesmo" - para nós mesmos somos "homens do desconhecimento"

(Nietzsche, Genealogia da moral). 
A noção de pessoa, fundamental na fenomenologia de Scheler, indica a unidade de concreto conjunto de atos, mediante os quais se doa a si mesmo, juntamente com o mundo externo e os outros, de modo imediato e absoluto. Assim, a pessoa é a unidade que se experimenta ao longo de um compreender-se (ou o outro), o qual transpassa cada ato específico. E se a pessoa se manifesta nas expressões corporais e no fluxo da vida psíquica, nem por isso tal compreensão é dependente da dimensão psicofísica da existência humana. Portanto, a pessoa não pode ser determinada como coisa pensada atrás e externa aos próprios vividos, mas como um ente que sabe de si, capaz de fazer-se perceptível, dando-se ao conhecimento na sua unicidade. Qual a possibilidade e de que espécie deste saber? Certamente, a compreensão do ser pessoal não se iguala nem deriva da percepção interna em sua interpretação tradicional, segundo a qual está limitada às vivências psíquicas próprias. Também não se equipara o saber dela resultante à autoconsciência do ego ou qualquer subjetiva inspeção de si.

Contudo, indubitavelmente, existe uma série de atos, bem como específico direcionamento destes atos, auxiliados por certas funções psíquicas, pelos quais o eu se percebe enquanto objeto, na medida em que cada indivíduo remete a atenção para si mesmo e descobre um conjunto particular de processos anímicos. Fenomenologicamente, é inegável a existência de uma modalidade de percepção referida a um conjunto de estados anímicos, que se caracteriza pelo fato do sujeito da percepção estar intimamente relacionado consigo, tendo o "si mesmo" como o objeto correlato do ato perceptivo - e deveria acrescentar, juntamente com Scheler (2000), relacionado a si de modo imediato e intuitivo. Pois, do contrário, o eu só poderia se apreender pela mediação do mundo físico com suas leis naturais e, ao conhecer-se, estaria também explicando-se a partir de conexões fisiológicas e causalidades físiconaturais, medindo sua própria vida psíquica ao aplicar a si os métodos das ciências positivas da natureza. Ademais, por meio de tal ato, o eu dirige-se para si mesmo enquanto individualizado e não como uma forma lógica supraindividual ou essência abstrata, isto é, como “sujeito lógico". Deste modo, ele experimenta e sabe de si de modo bastante determinado. Neste experimentar-se, o eu não é apenas consciente dos objetos percebidos na percepção externa, mas também chega a um saber individualizado de si — o resultado deste ato de índole particular que é a percepção 
interna. É a partir destas características próprias e positivas da intuição da vida interior como apreensão imediata de um eu singular e concreto que se pergunta: quais os limites deste ato diante da (auto)compreensão da pessoa? E em que condições internas e externas a percepção interna é transformada em mero instrumento do autoconhecimento e posta a serviço das metas e interpretações da cosmovisão natural? $\mathrm{Na}$ conexão destas duas perguntas, ao final, se perguntará pelas fontes da idolatria do autoconhecimento.

\section{A pessoa, a percepção do eu e 0 autoconhecimento}

Desde Descartes, compreende-se que a percepção interna é o ato responsável por descobrir o psíquico como um âmbito diferenciado e separado do mundo externo, pois, inerente ao sujeito pensante, a partir do que se coloca o ego como fundamento da verdade e condição primeira do conhecimento. Assim, o dar-se do eu a si mesmo seria o ponto incoativo do conhecer certo e seguro, de tal modo que se poderia afirmar que o saber de si seria, em última instância, pôr a si para si mesmo a partir de evidência absoluta de si. Em razão desta evidência, em contraposição à percepção externa, ato pelo qual o ego seria isento de enganos a seu respeito opinião que Scheler (2007, p. 215) admite ser o principal obstáculo para o conhecimento do mundo anímico. De qualquer modo, seguindo a compreensão dominante, a verdade de si se revelaria, em última instância, como e no autoconhecimento, na tomada da consciência dos fatos que constituem a realidade psíquica. Saber de si seria, em sua verdade profunda e oculta, autoconsciência. E o ato pelo qual se consumaria tal consciência de si se definira exclusivamente pela condição do objeto ser o eu. Neste caso, percepção interna equivale ao ato pelo qual "o espectador interno (innerliche Anschauende) se perceberia a 'si mesmo"' (SCHELER, 2009, p. 243, tradução minha). Para saber de si, bastaria, pois, que o ser humano, ao colocar-se como sujeito de uma intuição interna, lançasse o seu olhar para a sua realidade intrapsíquica, fixasse nela a sua atenção e se contemplasse, referindo-se aos conteúdos particulares de suas vivências e apreendendo-os fatos que, habitando o seu mundo interior, já estariam ali como algo pronto para se tomar posse ao longo do 
processo subjetivo de autoconhecimento. Então, dar-se-ia este enigmático ato chamado percepção interna.

Nesta direção da busca de apreender a totalidade do ser pessoal, sob o eixo do si mesmo psíquico, porém, mantido inquestionado na sua essência, se articulam, então, diversas compreensões, muitas vezes colocadas par a par em termos de significado, a saber: percepção interna, auto-observação ou observação dos conteúdos internos e psíquicos, autoconsciência, autoconhecimento. Daí que, inadvertidamente, o significado da percepção se equipara, tantas vezes, a uma inspeção de si pela qual, pouco a pouco, o sujeito se conhece, à medida que os conteúdos inconscientes dos fatos psíquicos sejam convertidos paulatinamente em conscientes. Admitindo o eu como ponto de partida para chegar ao conhecimento de si mesmo, este, ao dobrar-se sobre si mesmo, num processo de auto-observação, poderia alcançar as profundezas de si ao longo de uma "reflexão". Porém, tratar-se-ia de uma profundeza interna que, embora oposta ao mundo externo, se mostra tão "dada" (no sentido de meramente constatável) quanto os fatos desta esfera externa, essencialmente marcada pela efetividade. No horizonte deste presumido "saber reflexivo", tomado ainda na perspectiva da auto-observação e determinado de antemão como um ato exclusivamente intrapsíquico, a percepção interna seria o ato que, no muito, iria ao encontro de um conteúdo particular previamente existente ou se constituiria como vivência experiencial capaz de associar ou somar conteúdos vividos, relacionando-os e ordenando-os; não seria, de fato, o viver e experimentar mesmo de si como ato constituinte da individualidade do eu. Nisto, por certo, falta ainda uma compreensão de como a egoidade se doa como autêntico dado fenomenal, porém, sempre em correspondência ao ato que, possuindo a forma da percepção interna, caracteriza-se essencialmente pela apreensão intuitiva do eu particular. De outro modo, seria como o sujeito da observação tomasse a si sempre individualizado, mas de um modo em que esta tomada de posse não se constituísse a partir de um tom individualizado e individualizante, isto é, sem que o sujeito não estivesse presente como autor da própria experiência de autoperceber (SCHELER, 2000, p. 376-377) - o que é um contrassenso.

De imediato, deve-se notar que, em virtude deste emaranhamento confuso em torno do estado de coisas concernentes à percepção interna, toma-se 
indiscriminadamente o originário saber de si (a compreensão) concernente à doação originária da pessoa para ela mesma enquanto ato de concretização de si por sinônimo do ato mediante o qual o sujeito conhece a si mesmo ou é autoconsciente. Desta equiparação, resulta nada menos a impossibilidade de um saber de si que não seja essencialmente referenciado ao eu, de tal modo que o âmbito primário e absoluto de constituição de um saber da pessoa sobre si mesma deveria ser a subjetividade: percepção interna é definida essencialmente autopercepção. Na verdade, trata-se de um engano fundamental, que é não admitir a existência de um saber de si que não seja uma atividade consciente que parta do eu sentencioso e racionalmente reflexivo. Consequentemente, carece-se de uma radical compreensão de que modo o psíquico se constitui no modo próprio da evidência da percepção interna e, correlativamente, como se mostra o eu a partir de uma interpendência eidética entre ato e objeto. Enfim, não se apreende a diferença entre o saber originário da personalidade enquanto (auto)compreensão e aquele derivado, o autoconhecimento.

Se compreensão do si-mesmo permanece presa a este emaranhado, inevitavelmente a pessoa será subjugada aos procedimentos objetivantes do conhecer em suas diversas áreas e especialidades, reduzindo o saber de si a processos teoréticos — o que fornece as bases para uma ilusão designada idolatria do autoconhecimento. $\mathrm{Na}$ fonte desta idolatria ou egolatria, estaria o fato de ignorar que o objeto percebido (no caso, o eu), graças ao modo próprio de sua doação, pode se mostrar por aquilo que não é1. Em suma, não haveria a possibilidade de colocar a questão de um ser pessoal e de seu sentido, do saber de si a partir da realização mesma dos atos fundantes de uma concretude existencial singular. Radicalmente, não haveria pessoa, mas somente o sujeito lógico. Neste sentido, os "eus" com suas individualidades

\footnotetext{
${ }^{1}$ Característico para a definição de engano (Täuschung) é o fato de permanecer na esfera prélógica do comportamento das coisas visadas, especificamente, no horizonte da intuição e não, como no caso do erro, resultante da inadequação entre o âmbito intuitivo com o lógicopredicativo ou na passagem de um para o outro. $O$ engano surge do estado de coisas em que 0 dado intuível pode ele mesmo ludibriar o mirar da visão interna e externa, conduzindo a ilusões, já que a visão toma camadas "aparentes" de manifestação do ser como sendo a mais profunda. A raiz do engano, então, está no fenômeno que faz algo se passar por aquilo que não é e, portanto, não depende da atividade consciente de um sujeito que supõe algo em conflito com o dado intuído ao emitir um falso juízo (SCHELER, 2007, p. 226). Para outros esclarecimentos, conferir também a apropriação desta distinção feita por Merleau-Ponty (1999, p. 395-396).
} 
apreendidos no ato da percepção interna, na verdade, não seriam seres pessoais singulares em virtude da própria essência; seriam tão somente seres de razão, participantes de si próprios por um “saber' de ordem derivada, pois, realizado por atos pertinentes a uma esfera estritamente teorética:

Estes [seres, Wesen] não seriam "pessoas", mesmo que fossem participantes da percepção interna e externa e exercitassem assiduamente o conhecimento da natureza e da alma; ou seja, também quando elas tivessem encontrado o objeto (Gegenstand) "eu" em si mesmas e nos outros e colhido completamente com a visão, descrito e esclarecido a possível e fática experiência vivida "do eu" como de todos os eus individuais. O mesmo valeria exatamente para a essência (Wesen) de todos os conteúdos que fossem dados somente como projetos do ato volitivo. Seriam sujeitos (lógicos) de um querer - porém, pessoa nenhuma (SCHELER, 2000, p. 382, tradução minha).

Pessoa, portanto, não é coisa ou sustância alguma que o sujeito pensante apreende por detrás ou para além de seus vividos experienciais, mas a própria unidade que é coexperienciada ao longo destas experiências. A pessoa vive a si mesma, doa-se para si como presente em todas as suas vivências (não apenas naquelas completadas mediante os atos pelos quais retorna a si) e, neste fazer a experiência de viver a si, compreende-se. Contudo, tal doação não possui o caráter de uma apercepção pura, tal como em Kant. Pessoa, pois, não se define a partir de sujeito ciente de si como um "eu penso", que acompanharia todas as suas representações. É em base de tal princípio que é legítimo identificar seu modo de doar-se com a possibilidade do sujeito apresentar a si para si mesmo como "unidade transcendental da autoconsciência" (KANT, 2001, p. 158) e, nisto, determinar-se condição a priori de toda e qualquer representação. Pessoa, porém, não se confunde com o sujeito, seja ele cognoscitivo ou volitivo, com a sua prerrogativa de ser o único ente capaz de se pôr como fundamento substancial último e inabalável, certeza absoluta de si e de suas referências para coisas segundo os diversos interesses do viver humano. "O ser da pessoa jamais pode surgir do fato de um sujeito ser a partir de atos racionais segundo determinada legalidade" (SCHELER, 2000, p. 371, tradução minha), do que deriva sempre a concepção da pessoa como substância ou coisa. Pois, nesta direção, é pensado exclusivamente o eu que liga as representações (o "eu” do “eu penso"), assim como sua identidade e as condições a priori em virtude das quais se reconhece que determinada representação pertence a mim, mas não o sou, também sempre meu, de minha pessoa ou de outrem, que antecede em origem e essência o eu. Na unidade do ser-pessoa e do modo de que ela é apreendida em cada vivência, por certo, há algo de 
mais fundamental que na unidade subjetiva da autoconsciência advinda por uma apercepção pura. Por conseguinte, o ser sempre concreto e singular de minha pessoa, pelo qual ela não se reconhece simplesmente como proprietária de certa representação, mas antes diz "eu sou" ou "tu és", isto é, nomeia e compreende a singularidade de sua existência, não se limita à identidade e a atos do sujeito cônscio de si ao ligar as representações pertencentes a sua consciência.

Em vista de dirimir tal confusão e evitar as consequências acima para a determinação do sentido próprio da (auto)compreensão da pessoa e seu modo genuíno de doar-se, deve-se pressupor a possibilidade de uma esfera absoluta do saber de si, que ultrapassa a egoidade. Entretanto, para não ir além da meta deste estudo, fixemos no seguinte, precedentemente dito: se a percepção interna for esclarecida unicamente em base da determinação que seja o ato em que um sujeito, dirigindo-se a fatos intrapsíquicos, em vez de remeter-se para os fatos físicos e externos, far-se-á coincidir, sem mais, a "percepção interna" e "autopercepção" (SCHELER, 2009, p. 250). Dito de outro modo, a percepção de si mesmo, pura e inteiramente intrapsíquica, não passará de uma ficção, alerta Scheler (2009, p. 246).Contudo, não só o mundo interno se traduz e exterioriza-se nas expressões e outras modificações do corpo, assim como também é inteiramente possível apreender as vivências alheias com a mesma evidência e imediatidade com que o eu percebe as próprias. Nesta ficção, então, se esconderia que, rigorosamente, "percepção de si mesmo não se opõe à percepção externa, mas sim à percepção dos outros" (SCHELER, 2007, p. 228, tradução minha) ${ }^{2}$.

\footnotetext{
${ }^{2}$ A referida ficção, então, se esclarece amplamente pelo fato que a intuição do si mesmo, no horizonte delimitado à totalidade do mundo psíquico do eu, é apenas uma das esferas mais estreitas da percepção interna. Com efeito, ela pode se avançar para a interioridade do próximo e, superando os limites seletivos do sentido interno e os "muros" divisores entre a vida psíquica própria e a alheia, alcançar a amplidão da esfera da evidência da arquetípica vida psíquica de determinada comunidade ou da humanidade como tal. Trata-se da esfera de ser mais primordial, a saber, de um tu como tal ou de um eu em geral. Com ela, Scheler (2009, sobretudo p. 228-232) confere à percepção interna a envergadura da apreensão da anima de uma humanidade primitiva enquanto uma corrente de vividos experienciais, absolutamente indiferentes ao eu e ao tu, mas que, como tal, é a fonte da alteridade e da identidade originária dos singulares. É o problema central da percepção do eu alheio, cuja exposição detalhada é um objetivo que extrapola os limites do presente estudo.
} 
Deste modo, não é o tipo de objeto intencional que define a fratura e os possíveis liames entre a percepção externa e a interna. Contudo, com a denúncia da ficção supracitada não se afirma ingenuamente que o si-mesmo psíquico são seria um autêntico dado fenomenal ou objetos, dotado de determinado conteúdo materialintencional como tantos outros, de particular índole, cuja apreensão, portanto, não necessitaria de especial intuição. Pelo contrário, o psíquico é uma forma de existência que se manifesta para a intuição pertinente à percepção interna, é a "matéria do ser do como tal" (SCHELER, 2007, p. 232-33, tradução minha) que se doa na esfera do mundo interno. É um genuíno modo de ser, uma "forma" de existência (Form des Daseins), bem como de ser-doado (Gegebensein), isto é, de fazer-se presente, de tal modo que há sentido falar de percepção interna. Contudo, sem fazê-la um modo específico de perceber, oposto a outro, designado percepção externa, mas como uma direção diferente de um único modo do perceber como tal, visto que em cada vivência de um objeto externo é sempre dado de igual modo, originariamente, o indivíduo que se experimenta ao levar a cabo o ato da percepção externa. Separá-las em dois modos seria ainda pensar estas duas direções do perceber a partir das características dos objetos aos quais se remetem, recaindo em uma postura teorética, quando não na tentativa de determinar empiricamente a diferença entre ambas. Deste modo, psíquico é aquilo que se doa, juntamente com o físico, no mesmo e único modo de perceber, no qual comparecem, em esferas específicas, um contexto ou uma imbricação essencial de todos os momentos e elementos inerentes à constituição de conteúdos e objetos intencionais.

Em síntese, no mundo interior, também há também formas especiais de existência de fatos psíquicos e, então, uma materialidade psíquica, na medida em que aqueles são os dados de manifestações por meio das quais os objetos são constituídos em conformidade com as formas dos atos que os percebem. $\mathrm{Na}$ fenomenologia de Scheler (2007, p. 229-231), é explícita a tentativa de superar a rígida e nítida fratura entre mundo interno e externo, fundada na metafísica cartesiana, segundo a qual se admite o psíquico como a realidade privada de matéria, na medida em que ele se constituiria exclusivamente de atos intencionais e funções. Ao contrário, na perspectiva fenomenológica, no âmbito do psíquico, não só há o específico direcionamento do ato (para a esfera interna, a egoidade do eu), como também 
manifestações e atos com suas próprias qualidades e formas. Sobretudo, há uma modalidade particular de intuição, pura e privada de forma, que corresponde às essências que se colhem em atos e direções de atos que se nomeia, usualmente, por percepção interna. Desta feita, considerando a totalidade destes elementos necessários para definir o sentido da percepção interna, ressalta-se:

A percepção interna não é a percepção de algo independente desta percepção, prontamente fixado como "psíquico", através de definição, enquanto uma unidade genérica de objetos; "psíquico" é, senão, um significado, que sempre se preenche, quando tomamos esta direção especial de ato de uma percepção interna e quando, por assim dizer, a seguimos. "Psíquico" é aquilo que se manifesta por meio da percepção interna (SCHELER, 2007, p. 237, tradução minha).

Se o que define o objeto da percepção interna é um significado oriundo do sentido de um ato, não é uma qualidade qualquer, de objetos ou de atos, que a delimita da outra direção do perceber, a externa. Qualquer elemento estrutural que comparece na percepção externa também deverá se apresentar na interna. Significados, porém, não são coisas dadas; dão-se, isto é, preenchem-se tão somente dentro e ao longo do acontecimento do contexto significante e na dependência do sentido deste ou direção de sua realização. Assim, significados não dependem unicamente das experiências vivenciais e das relações a elas intercorrentes, mas do próprio viver que as anima; não só da qualidade e da forma dos atos, mas do fluir atuante em que os atos se realizam ou são consumados. De igual modo, não sendo as experiências vividas e significantes nenhuma operação abstrata, o significado se apresenta enquanto também se doa o seu objeto e conquanto ele se doe concretamente em suas particularidades e identidade - no caso percepção interna, o psíquico e, sendo este sempre determinado, o simesmo psíquico ou eu com sua egoidade.

Ora, o eu é um objeto idêntico, mas de modo tão originário que ele não só é "algo" identificável, ao ponto de ser sempre o mesmo, ou seja, de modo que o sentido de seu ser resida na sua identidade, mas também no sentido de que seus atos permitem a identificação de objetos ao evidenciar e colher-lhes a essência. De outro modo, ele não só é determinado, mas também determina e, sobretudo, ao determinar objetos, determina-se. Objetos idênticos correspondem a atos essencialmente idênticos ou identificadores. A percepção interna é um ato essencialmente idêntico ou capaz de identificação e a ela pertencente o eu, enquanto o objeto que se (con)figura na consumação mesma deste ato. E pertence de maneira essencial, não unilateral ou 
exteriormente. Antes, trata-se de uma pertinência recíproca, que forma um contexto de constituição em que as relações são copertinentes. Por conseguinte, o fenômeno do psíquico aparece no medium mesmo da percepção, em que o eu individualizante (enquanto autor) aparece a si mesmo enquanto se doa de forma individual (eu como o objeto do perceber interno). Assim, à forma da percepção interna corresponde, portanto, matéria da percepção como algo próprio. Ao mesmo tempo, então, o eu é a forma do ato da percepção interna, como ainda a matéria determinada do perceber. Daí que o eu não pode ser uma forma lógica abstrata, privada de todo preenchimento material, estabelecido como condição a priori da percepção de objetos da natureza dados à sensibilidade, ou seja, apenas um conceito transcendental isento de elementos empíricos que seria o "veículo de todos os conceitos em geral” (KANT, 2001, p. 353). É ele mesmo objeto entre objetos; e sua identidade somente subsiste na medida em que é sustentada pelo ato da percepção. Também por esta razão, não poderá ser um sujeito lógico enquanto uma abstração e forma genérica, mas sempre será constituído conforme a tonalidade que o eu vive e experiencia a si mesmo e a tudo que é ao entorno. Não há como o eu não ser bem determinado, já que é o datum particularizado que surge ao longo de um eu-individual-da-experiência-vivida (indivinduellen Erlebnisich) (SCHELER, 2000, p. 376). Em Wesen und Formen der Sympathie, o caráter original do eu e do ato de sua percepção é indicado nos seguintes termos:

\footnotetext{
Um "indivíduo" anímico (seelisches "Individuum") nunca é o mero "contexto" ou a "soma" de suas experiências vividas (Erlebnissse); ou uma "síntese" delas, cujo sujeito somente fosse a atividade da assim chamada consciência "supraindividual", uma "consciência em geral". Muito ao contrário, cada experiência vivida é ela mesma somente por meio de uma concreta experiência vivida (não mais de um puro conceito ou aspecto de tal experiência), de tal modo que nela, ao mesmo tempo, apreendo um indivíduo que é um eu, ou porque isto se torna para mim um símbolo para a permanência de tal indivíduo. Por esta razão, eu primeiramente apreendo do outro não uma única experiência vivida, mas sempre o caráter da totalidade psíquica do indivíduo em sua expressão total (SCHELER, 2009, p. 237-238, tradução minha).
}

No corpo, em que o eu se encontra encarnado, manifesta-se a individualidade da alma; em seus movimentos, estados, feições e qualidades de seus elementos anatômicos e em qualquer mudança destes aspectos, por mínima que seja, é possível apreender o eu, seu caráter, seu ânimo, o fluxo psíquico-vital e as transformações na totalidade anímica que estas pequenas mudanças revelam. Conclui-se que as expressões corporais do eu, portanto, são apenas símbolos da vida psíquica. Contudo, como ensina Bergson (2006), o conhecimento por símbolos, particular às ciências 
positivas, é relativo, pois está condenado a rodear a coisa, sem penetrar no seu interior e, assim, tê-la apenas em perspectivas ou pontos de vistas sucessivos que se prolongam numa série infinita. De símbolo em símbolo, a partir da análise deles segundo os modelos empíricos com suas leis específicas para as relações causais, temporais e formas de multiplicidade da existência material do mundo físico (SCHELER, 2007, p. 257, 266), somente se chegaria a uma soma das vivências. Deste modo, os símbolos, apenas por eles mesmos, são incapazes de completar uma visão da unidade da coisa; no caso do eu, são inaptos para apreender, como dito acima, "O caráter da totalidade psíquica do indivíduo em sua expressão total”. Por símbolos, então, a intimidade do eu, a particular interioridade dele mesmo, bem como o conteúdo da esfera interna do outro seriam dados somente por raciocínios de analogia (SCHELER, 2009, p. 21, 232-233): da percepção de movimentos expressivos alheios se conclui que, por serem semelhantes aos próprios, são conteúdos psíquicos iguais, porém, pertencentes ao próximo. Não haveria, então, uma percepção originária desde uma evidência imediata da singularidade de si e do outro, mas sempre mediata.

Necessária é, portanto, algo que confere à visão a capacidade de apreender a totalidade unitária da coisa, captá-la de "um só golpe na sua integralidade" (BERGSON, 2006, p. 185), que é a intuição. Por meio dela, faz-se ver que a apreensão da totalidade psíquica e particular do eu nas expressões corpóreas de um indivíduo exige um ato simples e imediato. Com isto, revela-se a ilusão de que toda (auto)observação pode levar à compreensão de um fato psíquico como o resultado de sua análise e explicação científica, pois ele, antes de ser fixado como mero "fato" do experimento, os conteúdos psíquicos que nele se doam já deve ser previamente compreendidos, simples e imediatamente, "dado que todo ato de possível observação já pressupõe a manifestação da essência do fato que está por ser observado" (SCHELER, 2009, p. 218, tradução minha). Enfim, os dados referentes ao mundo interno, apreendidos mediante a (auto)observação de símbolos ou fenômenos expressivos, deverão ser (co)pensados e (re)pensados pelo observador ao longo e depois de seu experimento, o que significa previamente compreender as expressões desde a sua fonte e sentido.

Segue-se daí que toda a descrição acima acerca da percepção interna e seus elementos constituintes ainda permaneceria um posicionamento de existência do eu 
com sua egoidade, de caráter teorético-representacional, se na base desta estrutura eidética de ato e objeto, bem como das relações que se estabelecem entre os atos e que manifestam o psíquico como um intricado de experiências vividas, não operasse de forma viva uma "intuição pura, privada de forma e fenomenologicamente demonstrável em relação às diferentes matérias" (SCHELER, 2000, p. 375). Como fonte da apreensão do (com)plexo de vivências que constituem o psíquico, no seio da percepção interna, encontra-se o simples intuir. Por graça disto, o eu é um dado positivo, um fato psíquico, total e abrangente de todas as experiências vividas, porém, não empiricamente constatável e, consequentemente, observável. Pelo contrário, na medida em que é acessível somente a uma intuição imediata e ao longo do apreender que a caracteriza, como postula Scheler (2000, p. 377), o eu é, cada vez, uma nova datidade e que se refaz a cada doação (eine jeweilig neue und neue Anschanungsgegebenheit). Eis a razão principal pela qual o eu não é um conteúdo, que poderia ser analisado, ordenado, na medida em que se separa as vivências constituintes do plexo psíquico ou as associa e as relaciona, somando-as em um conjunto. Porque se doa renovadamente, o eu é a totalidade de um plexo vivencial que se forma e complexa constantemente, sempre, porém, em necessária referência às fáticas experiências vividas, logo, particulares a cada indivíduo.

Do exposto, é dado afirmar que a percepção interna é autêntica forma de conhecimento do si mesmo, certo que no horizonte e dinamismo próprio de instauração do psíquico. Desde que fenomenologicamente compreendida, ela é um ato que retira o autoconhecimento daquela impostação empírico-teorética, a qual conduz à adoção da auto-observação como método de descoberta de conteúdos já dados. Ao mesmo tempo, ela rompe com a pretensão de uma consciência de si desencarnada da facticidade de quem busca se compreender, ilusoriamente, a partir de abstrações alijadas do eu individual. Ambas as impostações levam a enganos que põe em perigo a originalidade do perceber. De outro lado, na direção das concepções sensualistas da percepção, há os extravios em considerar a percepção interna numa relatividade e dependência da estrutura orgânica do corpo e, consequentemente, às funções e à fisiologia dos órgãos sensitivos. Todos estes desvirtuamentos, porém, não são um fato meramente negativo. Positivamente, eles revelam que, na maioria das vezes, não se atenta à totalidade particularizada e unitária do eu, de modo ela passa 
despercebida nas concepções teoréticas do perceber interno, desembocando em explicações causais e fisiológicas adequadas tão somente ao mundo físico. E há de se supor que os desvios são favorecidos pelo modo específico dos "objetos" da percepção se doarem e, correlativamente, às funções internas com seus "mecanismos psicofisiológicos", atuantes sobre o fundo do totalizante campo perceptivo ou influindo na base da unidade do fluxo vital das vivências anímicas, pelos quais aqueles são colhidos. Tais enganos mostram que, portanto, é preciso colocar em questão os limites do perceber interno, acentuando as razões pelas quais este ato é compreendido normalmente partir de sua submissão às concepções idolátrica do autoconhecimento, em última análise, resultantes de ilusões na captação do dado intuitivo.

\section{Os limites da percepção interna: a mediação do sentido interno e as fontes dos enganos}

Na percepção interna comparecem, em nodo análogo, os mesmos elementos estruturais da percepção do mundo externo. Ora, na terminologia sheleriana, o significado de mundo (do eu, do tu, da comunidade, do divino) é pensado desde o conceito de esfera, entendida como uma totalidade essencial previamente dada à posição de realidade de qualquer objeto possível como "fundo" (Hintergrund) (SCHELER, 2009, p. 231). Deste modo, o conceito de esfera remete a um princípio fenomenológico fundamental, segundo o qual a apreensão de cada coisa posta-diante (Gegenstand) da subjetividade pelos atos intencionais e o preenchimento dos conteúdos específicos se dão sob o suporte de uma originária unidade de um todo regional do ser. É, pois, no fundo de uma cercania de caráter eidético ou vastidão precisamente delimitada que cada coisa se destaca e, segundo determinado interesse, é percebida em detrimento de todas as outras que igualmente se posicionam na mesma esfera. No caso da percepção externa, na direção que se volta para os objetos físicos, esta se consuma dentro de um campo intuitivo próprio, do qual se aprende este ou aquele como algo aqui e agora. Por isto, ao perceber pertence não somente o remeter-se ou tender-se para a coisa destacada, mas igualmente, como diz Husserl (2009, p. 71), um “campo de intuições de fundo", não obstante este permaneça, na maioria das vezes, como a totalidade "subconsciente", irrefletida. Mas, se esta estrutura fenomênica não 
vale somente para o mundo externo, então, todo apreender é o destacar de uma esfera eidética que se abre como fundo de experiência, sob o qual o percebido surge e se constitui, segundo direções específicas da percepção, no fluxo dos atos percipientes. De outro modo, é preciso dizer que a percepção se deixa afetar apenas por um ou outro dado desta esfera cointuída, de tal modo que a percepção de cada coisa, na sua especificidade, é dependente de um sentimento ou afecção que tende para determinada referência, isto é, dirigida por um interesse da atenção que seleciona aquilo que chega a ser percebido do mundo circundante (HUSSERL, 1999, p. 91-92; SCHELER, 2008, p. 95 ; 2009, p. 246).

Em Liebe und Erkentnnis, Scheler (2008, p. 96, tradução minha) recorda que “as direções de nosso representar e perceber seguem as direções de nossos atos de tomar interesse e nosso amor e nosso ódio". Abstraindo-se, porém, destes aspectos axiológicos, cujo papel é de suma importância para determinar a direção e o grau do interesse, pergunta-se: por que a percepção interna se limita a selecionar dados particulares e deixa a totalidade sempre individual e material passar "despercebida". Isto é, por que o eu na sua singularidade e unidade, justamente no ato da percepção interna, não é percebido como evidentemente existente e fundo de cada vivência particularizada? De fato, saber de si, isto é, ter o si mesmo para si, na imediatidade de sua datidade, sem que ou eu esteja fragmentado em passado, presente e futuro é bem diferente que perceber vivências isoladas com seus conteúdos, sejam elas atuais ou passadas. Quando se desconsidera esta diferença, então, pode-se facilmente fazer coincidir a percepção interna com a tomada de nota ou conhecimento de conteúdos internos a partir da auto-observação.

A resposta vem da constatação da evidência que, na percepção interna, ao se dirigir intuitivamente à vida psíquica no seu todo, percebe-se apenas as vivências separadas no tempo e conforme a causalidade psíquica, com justa razão, em virtude da atuação intermediária de uma função analisadora e selecionadora: o sentido interno (SCHELER, p. 2007, p. 242). Então, entre a totalidade intuída da esfera interna e o parcial conteúdo percebido deve haver um sentido análogo ao da percepção externa: assim como entre a inteira esfera da natureza e o conteúdo (de)limitado a algum(s) objeto(s) notado(s) e sensorialmente percebido(s) se interpõe uma função sensível do corpo na unidade de suas sensações (o sentido externo), põe-se no medium ou no 
intermédio entre o eu percebido e o ato da percepção interna uma função que colhe apenas certas vivências. $\mathrm{Na}$ percepção dos dados psíquicos, portanto, atua uma sensibilidade específica para a apreensão do mundo interno e concretamente vinculada à unidade das experiências do corpo-próprio que, para Scheler (2009, p 250, 253), é aquela função que possui o papel de eleger, do intricado de vivências constituinte da vida psíquica, em dado momento, no tempo objetivo e fracionado, aquilo que é importante para o corpo vivido.

$\mathrm{Na}$ percepção interna o eu volta-se para si e se tem todas as suas vivências presentes para si mesmo. A rigor, não há vivências experienciais que são passadas, presentes e futuras; todas elas estão inteiramente atuando sob a vida psíquica, seja como um passado que sempre acompanha o eu ou como um futuro ainda não preenchido. Originariamente intuído, o eu deveria se dar nesta totalidade, fora da divisão do tempo objetivo; deixaria ver-se como uma vida interna plenamente temporal e não como uma vivência intratemporal com certo conteúdo momentaneamente determinado. Porém, neste dirigir imediato, visto ser dependente dos interesses do corpo-próprio, mostra-se unicamente como uma vida que se vive dentro do tempo fenomenal, impossível de ser apreendida fora do decurso dos processos anímicos interiormente percebidos - o que é possível somente no âmbito de uma esfera absoluta, constituída pelo puro realizar de atos livres, a saber, a esfera espiritual da pessoa enquanto aquele centro vital psicofisicamente indiferente que "vive inteiramente no tempo e consuma seu ato no tempo" (SCHELER, 2000, p. 384, tradução minha). O eu, entretanto, não é esta esfera eidética de existência absoluta e independente do corpo-próprio e, assim, a percepção interna está sempre intermediada pelo sentido interno. Mesmo que se associasse os diversos conteúdos atuais dos atos perceptivos, sintetizando-os com os conteúdos mnêmicos e expectantes, ainda que oriundos da recordação e espera imediatas, jamais se chegaria à totalidade que está na base da intuição interna. Consequentemente, é em razão da fisiologia ou mecanismo próprio do sentido interno, tão somente o que se manifesta como momentaneamente presente é notado na percepção interna (2007, p. 244).

Os limites da percepção, compreendida na sua unidade, se devem, em síntese, ao mecanismo psicofisiológico que, de um lado, a prende a limitado número de corpos físicos do mundo circundante, de outro, a algumas poucas manifestações da inteira 
vida psíquica. Para o reto entendimento desta conclusão, no mínimo, três observações são necessárias. Em primeiro lugar, Scheler (2007) deixa inteiramente explicito que, rigorosamente, o limite não reside nem na manifestação dos fenômenos da vida psíquica nem no conteúdo da intuição que os apreende, mas sim na captação analítica, seletiva e mediadora da concepção parcial do todo intuído. Urge-se esta distinção, para fazer jus à percepção interna, a fim de que ela não seja reduzida à fisiologia do sentido interno e, menos ainda, à neural-cerebral com seus transtornos na seleção dos conteúdos dos dados percebidos.

Em segundo lugar, uma vez que a limitada concepção é regida pelo interesse do corpo-próprio, não se trata de um suposto desprezo da corporalidade, mas sim do reconhecimento de que vida psíquica é faticamente experienciada num vínculo essencial com a condição da encarnação do viver humano e que a percepção da vida psíquica é influenciada pela legalidade da corporalidade vivida. Antes, é a admissão da irredutibilidade da corporeidade-própria e de sua particular datidade, de sua unidade psicofísica a nenhuma modalidade teorética de objetivação da percepção (SCHELER, 2000, p. 397). Todavia, isto não desemboca na supervalorização da corporalidadeprópria, visto que não se reconhece nela a datidade de uma estrutura unitária primordial, necessariamente psicofísica indiferenciada, isto é, que seja ela a fundar o ser pessoal. Contudo, tudo isto significa que, entre outros limites, que o eu possa tomar posse dos conteúdos do fluxo psíquico por meio da percepção interna unicamente dentro da ordenação tripartida do tempo e numa graduação intimamente relacionada com as variações da consciência corporal.

Por fim, é mister recordar que o sentido da legalidade da vida psíquica não é o da causalidade das ciências positivas da natureza, para a qual o efeito é sempre previsto conforme inalterável regularidade lógico-matemática. Pelo contrário, em se tratando da causalidade puramente psíquica, esta é inevitavelmente individual, pois indissociável da totalidade de cada eu, concretamente determinado. Por esta razão, a causalidade psíquica possui o caráter motivacional-compreensivo (SCHELER, 2000, p. 419); é compreendendo os concretos processos psíquicos, que o eu os define, porém, sem poder jamais abstraí-los da singular totalidade do ego, na qual se encontram, imanentes no fluxo vivido-experiencial de cada ego, os motivos para uma decisão ou outra. A especificidade desta modalidade de causalidade, bem se apreende do 
esclarecimento dado por Merleau-Ponty (1999, p. 348-349): "O motivo é um antecedente que só age por seu sentido, e é preciso acrescentar que é a decisão que afirma esse sentido como válido e que dá sua força e eficácia”. Decisão, então, é o fato psíquico ou a situação interior enquanto motivo assumido e validado. Em última instância, é para a dependência da causalidade dos atos livres da pessoa que os limites e aquelas variações e gradações da percepção interna da vida psíquica, mediada pelo sentido interno, deveriam ser fenomenologicamente reconduzidas.

Uma análise fenomenológica nesta direção está impossibilitada pela delimitação da presente consideração. Para a consumação do objetivo proposto, no entanto, é preciso ressaltar que é pela total desconsideração da fisiologia do sentido interno e das leis causais de sua fisiologia, sobrepondo a elas as leis físico-fisiológicas das ciências da natureza, por consequência, interpretando sensualisticamente a percepção, que desemboca, sem mais nem menos, na idolatria do autoconhecimento. Esta idolatria nasce, então, da ilusão que os processos vitais originários poderiam ser explicados pelas leis do mundo externo. A origem da idolatria, então, reside no movimento da esfera externa para a interna, conformando a segunda à primeira, no deslocamento que superpõe a percepção externa já naturalmente interpretada sobre a interna, em cuja base está a pretensão de conhecer e determinar o mecanismo psicofísico do sentido interno dissociando-o da totalidade do eu e, em seguida, interpretando-o desde a estrutura orgânica do corpo-próprio.

Nisto, em direção oposta à interpretação idealista da percepção interna e da tendência das ciências e do senso comum em superestimar as projeções do mundo interno na realidade externa como fonte dos erros mais ordinários, ressalta Scheler (2007, p. 257) que o ser humano tende, muito mais, a orientar-se pelo interesse predominante de compreender-se a partir de fatos externos, de sua específica modalidade de persistência, transformação e movimentação no espaço, transferindo para o mundo anímico relações e formas que pertencem unicamente à subsistência físico-material. Esta observação, por certo, não se equipara com aquela tendência que Heidegger (2006), nos termos da sua analítica existencial, descreveu como a possibilidade imprópria e cotidiana do ser humano em determinar sua existência a partir do ente intramundano com o qual ele lida nos seus ofícios, ocupações, interesses e prazeres, não obstante também seja a revelação da mesma tendência porém, descrita 
como a atitude interna da cosmovisão natural. Na maioria das vezes, esta insiste em ater-se à realidade psíquica por meio da física e não o contrário. Nesta objetivação equivocada, todo fato interno é dado à consciência, seja na representação como na volição, somente mediante estímulos físicos que excitam, em especial, os sentimentos sensíveis do corpo-próprio — símbolos oscilantes do sólido mundo externo, de tal modo que a atenção recai prioritariamente na esfera do corpo vivido ou na esfera psíquica. Paradoxalmente, a consequência é certa "patologia" amplamente difusa cujos sintomas é exacerbação dos sentimentos e contínua atenção para os atos internos. Assim, transferem-se os processos vividos para a esfera psíquica, confinando-os no mundo anímico sem correlação intencional com os objetos da esfera externa e, no fim, tudo deve ser buscado no horizonte desta sentimentalidade patologicamente subjetivada, também o saber de si. Com isto, ilude-se ao não se dar conta do seguinte: a concentração da atenção nos estados afetivos particulares, em vez de tornar mais ricos e vivos os conteúdos dos sentimentos - ao contrário das representações - acaba por fazê-los desvanecer e até destruí-los.

Esta tendência preponderante de transladar os fatos procedentes da percepção externa para os conteúdos da interna define a primeira fonte da idolatria do autoconhecimento. Entretanto, é na definição da segunda fonte que Scheler (2007, p. 266) explicita como os enganos favorecidos pelo sentido interno são levados a cabo pela impostação científica na explicação dos dados fenomênicos e mecanismos próprios à esfera interna. A segunda fonte, pois, consiste em transferir as formas e multiplicidades, que são próprias somente ao mundo físico, as relações causais e temporais entre causa e efeito que nele se estabelecem para os atos anímicos, bem como interpretar a simplicidade da totalidade conjuntural do eu a partir conjunções dos fatos físicos, possível somente a partir de associação, "síntese" e/ou identificação de objetos a posteriori. Com efeito, no mundo externo, as coisas se doam em modo isolado, separadas uma das outras no espaço e, no horizonte do tempo, são coadunadas no todo geralmente mediante relações causais; ademais, segundo a intuição natural, a multiplicidade de qualidades e formas delas são apenas símbolos para a percepção das coisas como tais e, então, não são a manifestação da unidade delas mesmas. Tudo isto, porém, revela a impostação teorética na compreensão da percepção, predominantemente prático-biológica (SCHELER, 2007, p 273), 
subjugando-a à (neuro)fisiologia dos sentimentos sensíveis. De fato, há tantas qualidades das coisas, quanto mais rica e pluralmente uma ou mais coisas sólidas podem estimular a sensibilidade com a imensa variação de suas cores, tonalidades, formas e de outras qualidades. De igual modo, é na dependência da estrutura orgânica do corpo-próprio que a variação das coisas sólidas podem ser aprendidas dentro das relações espaço-temporais, pois as suas mudanças e suas conjunções só podem se dar num fluxo, conforme é captado pelas funções sensitivas do sentido externo, que é instituído pela sucessão ou pela simultaneidade. Daí que somente a associação e a identificação é capaz de integrar na totalidade os fenômenos que antes eram apenas fatos isolados.

Transportar tudo isto para a esfera interna é grosso engano, fonte de uma ilusão que coloca a percepção interna a serviço da idolatria do autoconhecimento. Pois, para a intuição interna não é dado um eu-presente, o qual deveria ser associado num processo de identificação com o eu-passado a ser liberado do esquecimento pelos atos mnêmicos, bem como sintetizado ao eu-futuro, objeto antecipado pelos atos de aguardo, expectativa ou espera para se alcançar a totalidade do eu no fluxo de suas experiências vividas. Na percepção da vida psíquica, não se colhe "eus”, mas sim, a cada vez, um único eu unitário; o que aparece é sempre o fundo totalitário de um eu indiviso, mesmo que de forma vaga e difusa. O passado, o presente e o futuro do eu agem unitariamente em cada uma de suas experiências vividas, o que determina a unidade e a multiplicidade da consciência interna. Deste modo, a unidade da vida psíquica deve ser compreendida desde um modo sui generis da intuição, isto é, como apreensão primária de ser-junto, uma originária copresença de sentimentos, pensamentos e imagens; aquilo que se intui não é espaço nem tempo fisicamente determinados, mas de um estar recolhido de fatos psíquicos e conteúdos diversos na unidade indivisa do eu. É certo que, momentaneamente, o eu capta de si mesmo apenas certo conteúdo temporalmente localizado segundo a tripartição do tempo objetivo. Porém, este modo de captação, além da influência do mecanismo fisiológico do sentido interno, deve-se ao fato dela ser apenas apreensão do eu a partir da periferia de sua vida psíquica, em cuja região os fatos do fluxo da vida psíquica com os seus conteúdos aparentemente se particularizam em dados isolados. Ora, a periferia da consciência interna é o lugar em que a vida psíquica estabelece os liames com o corpo- 
próprio e, por isto, é irremediavelmente apreendida como se fosse um fato intratemporal e não uma experiência interna do tempo mesmo na sua unidade, possível unicamente a partir do ser-pessoa.

Contudo, nesta esfera de ser, não salta a percepção interna mediante um ato de compreensão da realização mesma do ato, pois ali se dá outro tipo de doação do ser humano para si mesmo que se caracteriza, entre outros aspectos, pelo fato de ser psicofisicamente indiferente, isto é, refratável a qualquer seleção fragmentadora e localização espaço-temporal. Enquanto doação de um centro capaz de realizar unitariamente a pluralidade de atos, é essencialmente impassível à objetivação. Atos, pois, somente deixam ser captados desde sua pura atividade e ao longo do sentido mesmo de sua própria realização — um segundo ato que é saber. Assim, o compreender tem o modo de saber reflexivo consumador dos próprios atos ou da correalização concomitante, sucessiva ou precedente dos atos alheios (SCHELER, 2000, 375, 386). Diante disto, para o efeito de conclusão da presente consideração, pode-se resumir que os limites da percepção interna relativamente ao autoconhecimento podem ser ditos em dois sentidos. Primeiramente, na direção de um significado negativo: a percepção interna, sendo apenas a direção da percepção como tal e no seu todo, não deve ser restringida ao significado de autopercepção, usualmente entendida como ato e instrumento da inspeção de si ou observação de conteúdo internos objetivamente pré-dados; somente assim se mostra quando não é distinguida do sentido interno e submetida a fisiologia deste último à legalidade e relações causais do mundo externo. Porém, limites devem também ser entendidos no sentido positivo de demarcação e definição de possibilidade. Neste segundo sentido, deve-se considerar que o autêntico autoconhecimento, o originário saber de si exige o encontro e captação compreensiva do todo em que desde sempre nós, como pessoas, sempre já nos situamos, a partir do qual inclusive o eu singular é compreendido na sua unicidade e concreção. Não bastam, pois, a seleção de eventos singulares e a objetivação de fatos isolados - metas para as quais a mera autoobservação já seria suficiente —, mas sim uma reflexão sobre si, vivida e cumprida como consumação de atos, capaz de fazer a percepção ultrapassar para a esfera ontológica responsável pelo recolhimento da pluralidade existente no interior da totalidade do eu. Trata-se da esfera ab-soluta, que sempre se transforma inteira e 
unitariamente, fazendo com que, cada vez, o eu assuma esta ou aquela concreção na sua totalidade. Exigir da percepção interna tal (ultra)passagem é fazê-la ir muito além da sua possibilidade de devolver o eu para si mesmo. Seria extrapolar os limites da intuição do todo que ela já é. Talvez em razão desta ludibriante exigência, como diz Nietzsche, somos os homens do desconhecimento: distantes de nós mesmos.

\section{Referências}

BERGSON, H. Introdução à metafísica. In: BERGSON, H. O pensamento e o movente. São Paulo: Martins Fontes, 2006. p. 183-234.

HEIDEGGER, M. Sein und Zeit. Tübingen: Max Niemeyer, 2006.

HUSSERL, E. Erfahrung und Urteil. Hamburger: Felix Meiner, 1999.

HUSSERL, E. Ideen zu einer reinen Phänomenologie und phänomenologischen Philosophie. Hamburger: Felix Meiner, 2009.

MERLEAU-PONTY, M. Fenomenologia da percep̧̧ão. São Paulo: Martins Fontes, 1999.

KANT, I. Crítica da rąão pura. Lisboa: Calouste Gulbekian, 2001.

NIETZSCHE, F. Genealogia da moral. São Paulo: Companhia das Letras, 1998.

SCHELER, M. Der Formalismus in der Ethik und die materiale Wertethik. GW 2. Bonn: Bouvier, 2000.

SCHELER, M. Die Idole der Selbsterknntnis. In: SCHELER, M. Vom Umstury der Werte. GW 3. Bonn: Bouvier, 2007. p. 213-292.

SCHELER, M. Liebe und Erkenntnis. In: SCHELER, M. Schriften zur Soziologie und Weltanschauungslehre. GW 6. Bonn: Bouvier, 2008. p. 77-98.

SCHELER, M. Wesen und Formen der Sympathie. GW 7. Bonn: Bouvier, 2009.

RECEBIDO: 19/04/2019

RECEIVED: 04/19/2019

APROVADO: 27/06/2019

APPROVED: 06/27/2019 